\title{
Probiotics decrease the stress response and intestinal permeability of term neonates with low Apgar scores
}

\author{
JIE WU, JUANLI ZHANG, JING CHEN and YAMEI HAN
}

The Second Department of Neonatology, The Second Hospital of Lanzhou University, Lanzhou, Gansu 730000, P.R. China

Received October 16, 2018; Accepted April 2, 2019

DOI: $10.3892 / \mathrm{etm} .2019 .8107$

\begin{abstract}
To observe the effect of probiotics on the stress responses and intestinal permeability of term neonates with low Apgar scores, the present study retrospectively analyzed the clinical data of 78 term neonates (42 males and 36 females). In the control group $(n=38)$, total parenteral nutrition and comprehensive treatment (anti-infection therapy) were provided. In the observation group $(n=40)$, the neonates were administered Lactobacillus Complex Capsules in addition to the control group treatment. The corticotropin-releasing factor level was determined using ELISA; cortisol levels were determined using a radioimmunoprecipitation assay; D-lactate and diamine oxidase levels were determined using ultraviolet spectrometry; procalcitonin levels were determined using ECL; and C-reactive protein levels were determined using a protein analyzer. Following treatment, the levels of all parameters were lower in the observation group compared with the control group, and the differences were statistically significant $(\mathrm{P}<0.05)$. In the observation group, the daily milk intake was $16.57 \pm 2.58 \mathrm{ml}$, which was significantly higher than that of the control group $(13.26 \pm 1.87 \mathrm{ml})$, while the length of hospital stay and total parenteral nutrition time, which were $12.31 \pm 2.02$ and $6.21 \pm 1.26$ days, respectively, in the observation group, were significantly shorter than those of the control group $(14.86 \pm 2.58$ and $8.86 \pm 1.78$ days, respectively), and the differences were statistically significant $(\mathrm{P}<0.001)$. The results of the present study suggested that probiotics can ameliorate the stress response and intestinal permeability of term neonates with low Apgar scores, thereby, facilitating gastrointestinal function recovery.
\end{abstract}

Correspondence to: Dr Yamei Han, The Second Department of Neonatology, The Second Hospital of Lanzhou University, 82 Suiyingmen, Chengguan, Lanzhou, Gansu 730000, P.R. China E-mail: yameihanyx@163.com

Key words: term neonates, low Apgar score, probiotics, stress response, intestinal permeability

\section{Introduction}

Neonatal asphyxia refers to an anomaly in the respiration of neonates, caused by various factors, such as inadequate oxygen levels in the mother's blood or lowered respiration rates, before, during or after birth, that can damage multiple systems, and involves severe sequelae or can even cause mortality (1). Neonatal asphyxia usually arises as hypoxia, ischemia and abnormal metabolism; respiratory failure blocks alveolar gas exchange, which causes hypoxia (2). In neonates, the systemic and organ damage severity is proportionately associated with the severity of hypoxia (3). Out of all neonates, $\sim 4,000,000$ succumb to neonatal asphyxia, accounting for nearly $23 \%$ of cases of mortality in developing countries in $2013(4,5)$. A previous study demonstrated that neonatal asphyxia is a major cause of mortality within 1 week after birth, and a factor contributing to perinatal mortality, neurologic handicap and developmental dysfunction (6). The Apgar scale is a convenient and widely accepted method that is frequently used to evaluate neonatal asphyxia; a 1-min Apgar score $<7$ suggests mild asphyxia, while a score $<3$ suggests severe asphyxia $(7,8)$.

Perinatal hypoxia and infection may result in potent postnatal stress responses, impacting the neuroendocrine and gastrointestinal systems $(9,10)$. The decrease in gastrointestinal permeability and increased intestinal inflammation further contribute to systemic organ dysfunction, since inflammatory factors pass through the intestinal mucosa (11). Probiotics are characterized by their ability to sustain the microecological balance within the intestines, and regulate the neuroendocrine functions in stress responses. They can protect the intestinal mucosa and ameliorate intestinal barrier function by facilitating cell proliferation and migration, which prevents cell apoptosis and enhance sprotein synthesis (12). A study demonstrated that probiotics can serve as an auxiliary treatment for stress-induced intestinal responses in neonatal mice, with significant improvements noted in gastrointestinal function (13).

Since, to the best of our knowledge, no studies have reported the stress response and intestinal permeability of term neonates with low Apgar scores, the present study aimed to elucidate the effect of probiotics on the stress responses and intestinal permeability of term neonates with low Apgar scores to provide a theoretical basis for clinical treatment. 


\section{Materials and methods}

General materials. The present study retrospectively analyzed the clinical data of 78 term neonates (42 males and 36 females) who were admitted to the Department of Neonatology at The Second Hospital of Lanzhou University (Lanzhou, China) for treatment between March 2017 and March 2018. Neonates born to mothers with a history of smoking or drug abuse, metabolic depression, hypertension during pregnancy, and acute infectious diseases were excluded from the present study. Additionally, all neonates with congenital heart disease, early-stage infection, aspiration pneumonia, gastrointestinal deformity or bleeding were excluded from the present study. Neonates were born at 37-41 weeks' gestation, weighed 2-4 kg and had Apgar scores of $<7$ points (14). In the control group $(n=38)$, total parenteral nutrition and comprehensive treatment (anti-infection therapy) were provided; in the observation group ( $\mathrm{n}=40)$, Lactobacillus Complex Capsules were administered to the neonates in addition to the control group treatment. Due to ethical reasons, a placebo only treatment was not approved. The present study was approved by the Ethics Committee of The Second Hospital of Lanzhou University, and the family of each neonate provided written informed consent.

Treatment methods. Following resuscitation, neonates in the control group received total parenteral nutrition and anti-infection therapy, in addition to regular nursing, which is standard treatment. Breast feeding was prioritized, but formula milk (Mead Johnson \& Company, LLC) was considered, and the milk intake was increased according to the condition of the neonate. During the treatment period, a number of neonates were infected and then received anti-infection therapy. The anti-infection therapy regimen was: Neonates were given ampicillin (100 mg/kg/day) for 3 days. Neonates that had a positive penicillin skin test were given cefazolin ( $50 \mathrm{mg} / \mathrm{kg} /$ day) but not ampicillin for 3 days. On the third day, neonates with normal peripheral blood C-reactive protein (CRP) levels stopped antibiotics treatment. When the intake was $\geq 120 \mathrm{ml} / \mathrm{kg} /$ day, the feeds were gradually transitioned to total parenteral nutrition. In addition to the treatment provided in the control group, neonates in the observation group were given probiotics treatment and were administered with Bifidobacterium triple live capsules (Shanghai Shanyao Xinyi Pharmaceutical Co., Ltd.; Guoyao Zhunzi approval no. S10950032). Each capsule contained $210 \mathrm{mg}$ powder, and the number of live bacteria was $>1.0 \times 10^{7}$ $\mathrm{CFU}$. The capsule was dissolved in warm water $\left(<40^{\circ} \mathrm{C}\right)$, and half a capsule was administered twice/day for 7 consecutive days.

Detection of indices of stress response and intestinal permeability. At 1 day before treatment and 7 days after treatment, $2 \mathrm{ml}$ of venous blood was drawn from the neonates prior to the intravenous infusion and breast feeding, and the serum was isolated via centrifugation at $1,500 \mathrm{x} \mathrm{g}$ for $5 \mathrm{~min}$ at $25-30^{\circ} \mathrm{C}$ for later use. Corticotropin-releasing factor (CRF) levels were determined using ELISA (cat. no. DECO0324; Beijing Zhongke Quality Inspection Biotechnology Co., Ltd.), cortisol using a radioimmunoprecipitation assay (cat. no. 2114-500; Biovision, Inc.), D-lactate and diamine oxidase (DAO) using an ultraviolet spectrometer (UVS-99; Avans Biotechnology Inc.), procalcitonin (PCT) using ECL (cat. no. 1705060; Bio-Rad Laboratories, Inc.), and CRP using a protein analyzer (cat. no. HC01001319; Gerhardt $\mathrm{GmbH}$ ). All procedures were conducted in strict accordance with the kit instructions, and each experiment was conducted in triplicate and the results were averaged. Additionally, the mean daily milk intake during 7 days of treatment, length of hospital stay (LOS) and total parenteral nutrition duration were recorded.

Radioimmunoprecipitation assay was performed as follows: A total of $10 \mu \mathrm{l}$ cortisol blank serum and $10 \mu \mathrm{l}$ serum samples were added to two coating tubes respectively. Each tube was added with $1.0 \mathrm{ml}$ labelling buffer solution and mixed by low speed vortex at $37^{\circ} \mathrm{C}$ for $46 \mathrm{~min}$, following which excess liquid was removed. ${ }^{125}$ Iodine-labeled cortisol in the remaining liquid was then counted in the $\gamma$-counter for $1 \mathrm{~min}$ and cortisol concentration was calculated using a standard cortisol curve at 1,3,10,25 and $60 \mu \mathrm{g} / \mathrm{dl}$ with repetitions of the steps described above. ECL was performed using a fully automated chemiluminescence immunoassay analyzer (SMART 300; Chongqing Keysmile Biotechnology Co., Ltd.)

Statistical analysis. SPSS software (version 17.0; SPSS, Inc.) was utilized for the data analyses. Enumeration data were compared using a $\chi^{2}$ test. Measurement data are presented as the means \pm SD and were compared using a Kolmogorov-Smirnov test. All data was normally distributed and analyzed using at-test. The intragroup comparisons before and after treatment were conducted with a paired t-test. Repeated measures ANOVA with Bonferroni post hoc test was used for multiple comparisons. All data were calculated from three experiments. $\mathrm{P}<0.05$ was considered to indicate a statistically significant difference.

\section{Results}

Comparison of general data. There were no significant differences identified in gestational age, sex, weight, Apgar score, type of birth and intrauterine hypoxia history between the observation and control groups ( $\mathrm{P}>0.05$; Table I).

Stress response of neonates before vs. after treatment. The cortisol, CRF and CRP levels were significantly lower after treatment compared with before treatment in the two groups $(\mathrm{P}<0.001)$. Before treatment, there were no significant intergroup differences $(\mathrm{P}>0.05)$, but after treatment, the levels in the observation group were all significantly lower than those in the control group $(\mathrm{P}<0.05$; Fig. 1; Table II).

Intestinal permeability of neonates before vs. after treatment. The D-lactate, PCT and DAO levels of the observation and control groups before treatment were $1.59 \pm 0.28$ and $1.57 \pm 0.26 \mathrm{mM}, 1.08 \pm 0.15$ and $1.05 \pm 0.13 \mathrm{ng} / \mathrm{l}$, and $18.62 \pm 3.14$ and $18.12 \pm 2.98 \mathrm{U} / 1$, respectively. The D-lactate, PCT and DAO levels of the observation and control groups after treatment were $0.68 \pm 0.12$ and $1.09 \pm 0.18 \mathrm{mM}, 0.24 \pm 0.05$ and $0.62 \pm 0.08 \mathrm{ng} / \mathrm{l}$, and $5.63 \pm 1.35$ and $9.82 \pm 2.46 \mathrm{U} / 1$, respectively. The D-lactate, PCT and DAO levels were significantly lower 
Table I. Comparison of the general data of the observation and control groups.

\begin{tabular}{|c|c|c|c|c|}
\hline Factors & Observation group $(\mathrm{n}=40), \mathrm{n}(\%)$ & Control group $(\mathrm{n}=38), \mathrm{n}(\%)$ & t or $\chi^{2}$ & P-value \\
\hline Sex & & & 1.251 & 0.364 \\
\hline Male & $24(60.00)$ & $18(47.37)$ & & \\
\hline Female & $16(40.00)$ & $20(52.63)$ & & \\
\hline Gestational age (weeks) & $38.96 \pm 1.02$ & $38.73 \pm 0.98$ & 1.015 & 0.314 \\
\hline Height $(\mathrm{cm})$ & $48.63 \pm 3.56$ & $49.04 \pm 2.97$ & 0.551 & 0.583 \\
\hline Weight (kg) & $3.86 \pm 0.38$ & $3.77 \pm 0.34$ & 1.100 & 0.275 \\
\hline 1-min Apgar score & $5.26 \pm 0.81$ & $5.41 \pm 0.89$ & 0.779 & 0.438 \\
\hline 5-min Apgar score & $6.41 \pm 1.26$ & $6.58 \pm 1.12$ & 0.629 & 0.532 \\
\hline Type of birth & & & 0.425 & 0.607 \\
\hline Natural labor & $9(22.50)$ & $11(28.95)$ & & \\
\hline Cesarean section & $31(77.50)$ & $27(71.05)$ & & \\
\hline Intrauterine hypoxia & & & 0.167 & 0.815 \\
\hline Yes & $26(65.00)$ & $23(60.53)$ & & \\
\hline No & $14(35.00)$ & $15(39.47)$ & & \\
\hline
\end{tabular}
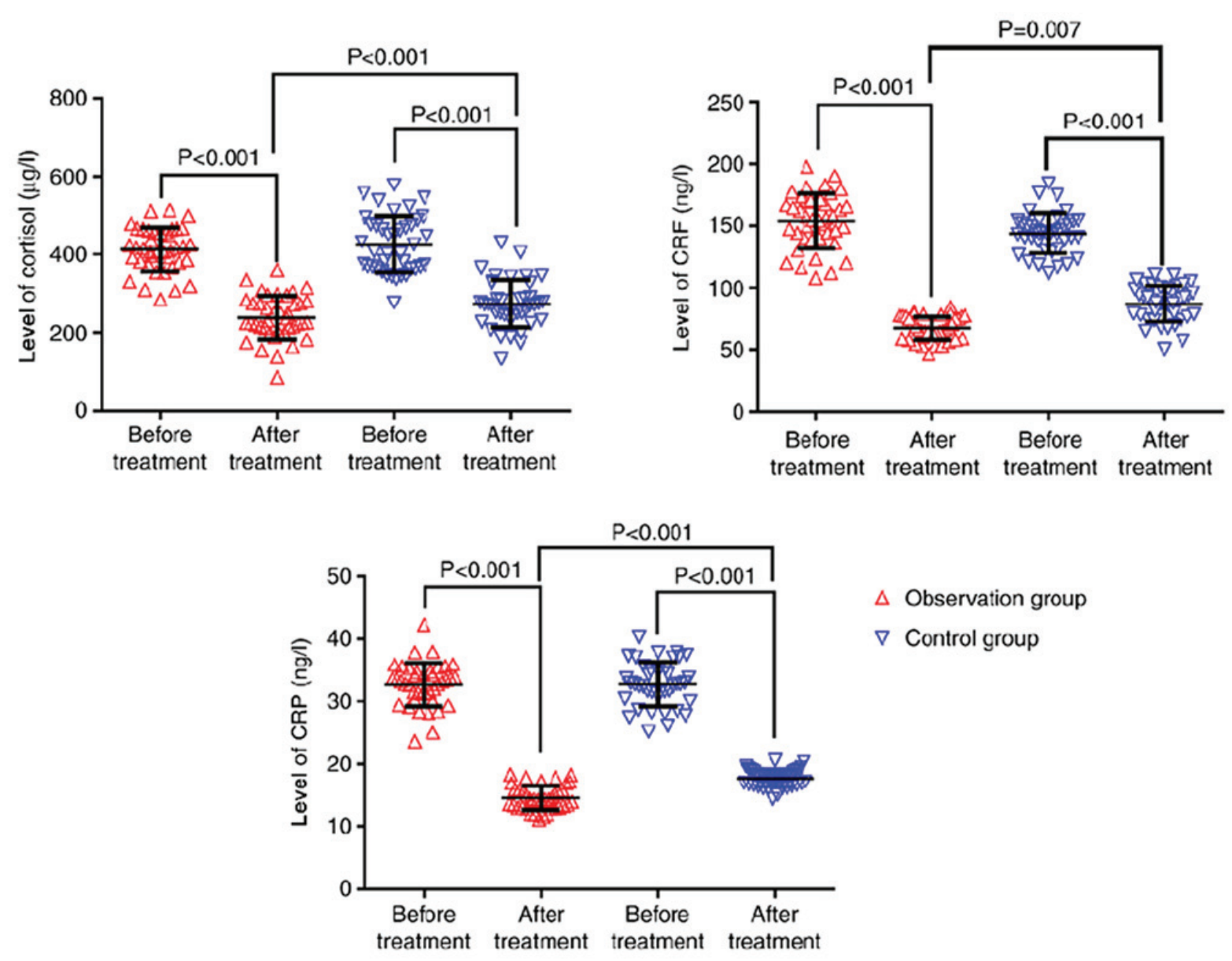

Figure 1. Comparison of stress indexes in the observation and control groups before and after treatment. CRF, corticotropin-releasing factor; CRP, C-reactive protein.

after treatment compared with before treatment in the two groups $(\mathrm{P}<0.001)$. Before treatment, there were no significant intergroup differences $(\mathrm{P}>0.05)$; however, after treatment, the levels in the observation group were all significantly lower than those in the control group ( $\mathrm{P}<0.001$; Fig. 2; Table III).
Gastrointestinalfunction recovery of neonates. The mean daily milk intake was significantly higher in the observation group $(16.57 \pm 2.58 \mathrm{ml})$ than in the control group $(13.26 \pm 1.87 \mathrm{ml})$, while the mean LOS and total parenteral nutrition duration of the observation group $(12.31 \pm 2.02$ and $6.21 \pm 1.26$ days $)$ 
Table II. Comparison of stress responses of neonates before vs. after treatment in the observation and control groups.

\begin{tabular}{|c|c|c|c|c|c|}
\hline Group & Number (n) & Time point & Cortisol $(\mu \mathrm{g} / \mathrm{l})$ & CRF (ng/l) & CRP (ng/l) \\
\hline \multirow[t]{4}{*}{ Observation } & 40 & Before treatment & $147.56 \pm 21.05$ & $421.65 \pm 63.75$ & $32.53 \pm 3.16$ \\
\hline & & After treatment & $68.63 \pm 11.58^{\mathrm{a}}$ & $235.82 \pm 42.32^{\mathrm{a}}$ & $14.64 \pm 1.65^{\mathrm{a}}$ \\
\hline & & $\mathrm{t}$ & 20.78 & 15.36 & 31.74 \\
\hline & & P-value & $<0.001$ & $<0.001$ & $<0.001$ \\
\hline \multirow[t]{4}{*}{ Control } & 38 & Before treatment & $144.67 \pm 19.68$ & $416.58 \pm 76.15$ & $31.78 \pm 3.56$ \\
\hline & & After treatment & $84.62 \pm 14.53$ & $265.37 \pm 51.26$ & $17.35 \pm 1.52$ \\
\hline & & $\mathrm{t}$ & 15.13 & 10.15 & 22.98 \\
\hline & & P-value & $<0.001$ & $<0.001$ & $<0.001$ \\
\hline
\end{tabular}

${ }^{\text {aP }}<001$ vs. control group. CRF, corticotropin-releasing factor; CRP, C-reactive protein.
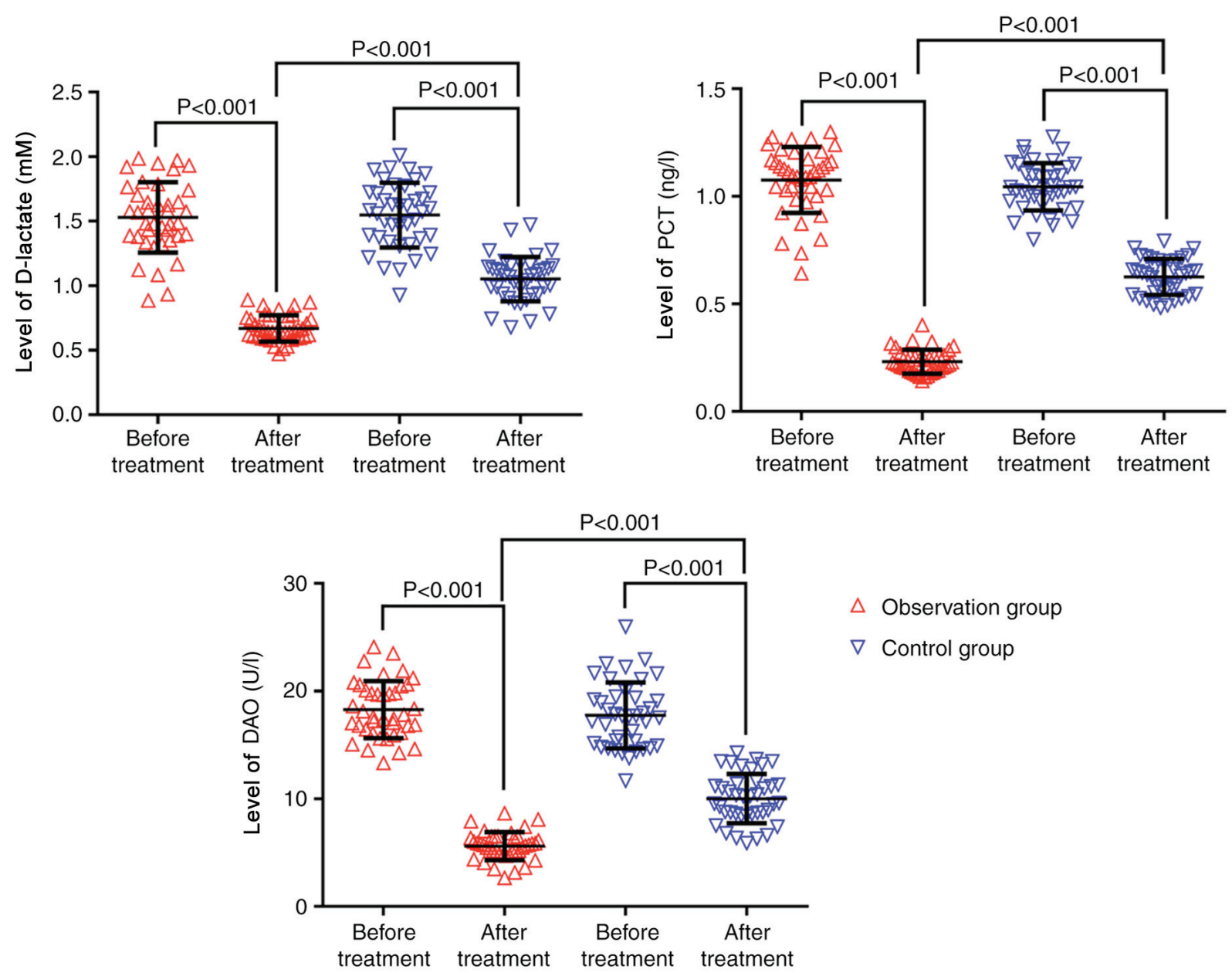

Figure 2. Comparison of intestinal permeability in the observation and control groups of neonates before and after treatment. DAO, diamine oxidase; PCT, procalcitonin.

were significantly shorter than those of the control group (14.86 \pm 2.58 and $8.86 \pm 1.78$ days; $\mathrm{P}<0.001$; Fig. 3 ; Table IV).

Infections during treatment. In the observation and control groups, there were 4 cases $(10.0 \%)$ and 11 cases $(28.95 \%)$ with infections during the treatment. The occurrence of infection in the observation group was significantly lower than that in the control group $(\mathrm{P}<0.05)$. In the observation group, one case of umbilical inflammation and three cases of bacterial pneumonia occurred. In the control group, two cases of umbilical inflammation, one case of scleredema, one case of impetigo and seven cases of bacterial pneumonia occurred (Table V). No sepsis and other infectious diseases, including bacterial meningitis, occurred in either group. All infections were controlled after treatment with the anti-infective regimen. 
Table III. Comparison of intestinal permeability of neonates before vs. after treatment in the observation and control groups.

\begin{tabular}{|c|c|c|c|c|c|}
\hline Group & Number (n) & Time point & D-lactate (mM) & PCT (ng/l) & DAO (U/l) \\
\hline \multirow[t]{4}{*}{ Observation } & 40 & Before treatment & $1.59 \pm 0.28$ & $1.08 \pm 0.15$ & $18.62 \pm 3.14$ \\
\hline & & After treatment & $0.68 \pm 0.12^{\mathrm{a}}$ & $0.24 \pm 0.05^{\mathrm{a}}$ & $5.63 \pm 1.35^{\mathrm{a}}$ \\
\hline & & $\mathrm{t}$ & 18.89 & 33.60 & 24.04 \\
\hline & & P-value & $<0.001$ & $<0.001$ & $<0.001$ \\
\hline \multirow[t]{4}{*}{ Control } & 38 & Before treatment & $1.57 \pm 0.26$ & $1.05 \pm 0.13$ & $18.12 \pm 2.98$ \\
\hline & & After treatment & $1.09 \pm 0.18$ & $0.62 \pm 0.08$ & $9.82 \pm 2.46$ \\
\hline & & $\mathrm{t}$ & 9.433 & 17.48 & 13.24 \\
\hline & & P-value & $<0.001$ & $<0.001$ & $<0.001$ \\
\hline
\end{tabular}

${ }^{\mathrm{a}}<001$ vs. control group. DAO, diamine oxidase; PCT, procalcitonin.
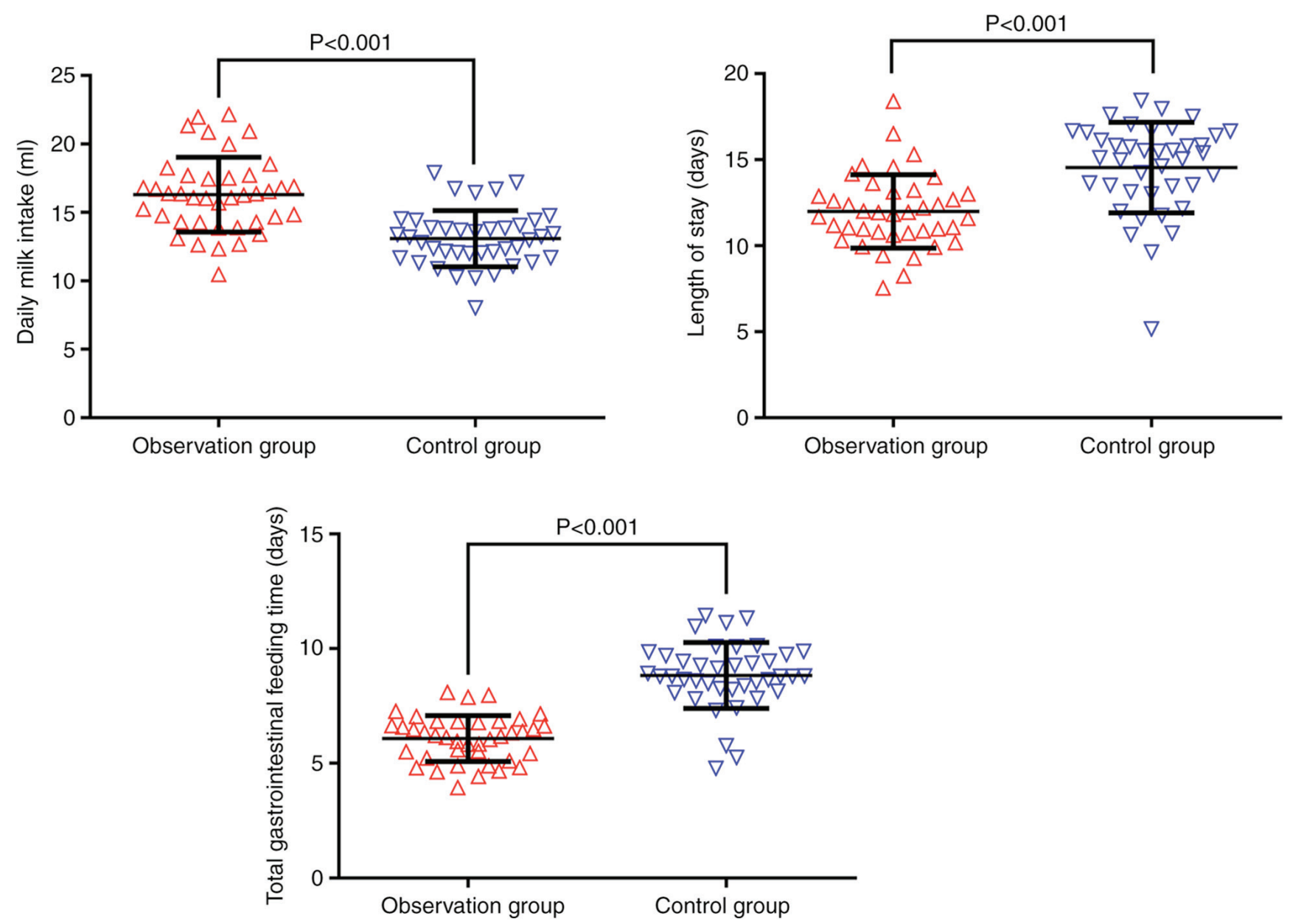

Figure 3. Comparison of intestinal tract recovery in the observation and control groups of neonates.

\section{Discussion}

Neonates with low Apgar scores are more susceptible to hypoxia and ischemia, which cause organ damage and functional anomalies (15). Due to the vulnerability of the neonatal gastrointestinal tract mucosa this can result in abdominal distension, milk regurgitation or even necrotic colitis (16). The neonatal gastrointestinal tract is developing, which makes it more vulnerable to bacterial invasion via the gut due to decreased amounts of bile acids and gastric acid, particularly in the presence of mucosal damage (17). An animal experiment revealed that probiotics can regulate intestinal barrier function long after the stress responses (18). Additionally, a clinical trial demonstrated that probiotics can improve epithelial barrier function (19). Therefore, it is rational to use probiotics in the treatment of stress responses and intestinal permeability in cases of neonatal asphyxia. 
Table IV. Comparison of gastrointestinal function recovery of neonates before vs. after treatment in the observation and control groups.

\begin{tabular}{lcccc}
\hline Group & Number $(\mathrm{n})$ & Daily milk intake $(\mathrm{ml})$ & Length of stay in hospital (days) & $\begin{array}{c}\text { Total gastrointestinal } \\
\text { feeding time (days) }\end{array}$ \\
\hline Observation & 40 & $16.57 \pm 2.58$ & $12.31 \pm 2.02$ & $6.21 \pm 1.26$ \\
Control & 38 & $13.26 \pm 1.87$ & $14.86 \pm 2.58$ & $8.86 \pm 1.78$ \\
T & & 6.459 & 4.874 & 7.619 \\
P-value & $<0.001$ & $<0.001$ & $<0.001$ \\
\hline
\end{tabular}

Table V. Comparison of the infections in the observation and control groups.

\begin{tabular}{|c|c|c|c|c|c|c|}
\hline Group & Number (n) & $\begin{array}{c}\text { Umbilical } \\
\text { inflammation (n) }\end{array}$ & $\begin{array}{c}\text { Bacterial } \\
\text { pneumonia (n) }\end{array}$ & Scleredema (n) & Impetigo (n) & $\begin{array}{c}\text { Total infection, } \\
\mathrm{n}(\%)\end{array}$ \\
\hline Observation & 40 & 1 & 3 & 0 & 0 & $4(10.00)$ \\
\hline Control & 38 & 2 & 7 & 1 & 1 & $11(28.95)$ \\
\hline $\mathrm{t}$ & & & & & & 4.504 \\
\hline P-value & & & & & & 0.034 \\
\hline
\end{tabular}

The severity of neonatal asphyxia is associated with the circulating cortisol level (20). CRF, a neuroendocrine peptide composed of several amino acids, can regulate stress responses in humans and animals (21). In neonatal blood, CRP levels are regulated by multiple factors, including neonatal asphyxia, intracranial infection, premature rupture of the fetal membranes and marked alterations in humoral immune responses after birth (22). Therefore, in the present study, cortisol, CRF and CRP levels served as indicators of the degree of the stress response.

Damage to the intestinal mucosa also affects the microecological balance in the intestinal bacterial community due to the production of large amounts of D-lactate which can be rapidly delivered into the blood circulation due to increased intestinal permeability (23). Additionally, damage to the intestinal mucosa and an increase in intestinal permeability enhance DAO activity (24). A study on PCT that mainly focused on acute infections suggested that PCT levels are physiologically increased following premature birth, primarily due to neonatal asphyxia (25). Thus, D-lactate, PCT and DAO were selected as indicators of intestinal permeability in the present study.

In the present study, the levels of cortisol, CRF, CRP, D-lactate, PCT and DAO in the observation and control groups were significantly lower after treatment compared with before treatment $(\mathrm{P}<0.001)$. Prior to treatment, intergroup comparisons exhibited no statistically significant differences in the levels of cortisol, CRF, CRP, D-lactate, PCT and DAO $(\mathrm{P}>0.05)$, whereas after treatment, these levels in the observation group were all significantly lower than those in the control group $(\mathrm{P}<0.05)$. These results suggested that treatment in combination with probiotics can mitigate the stress response and intestinal permeability of term neonates with low Apgar scores.
Among the few studies reporting on asphyxia in term neonates, some reported that probiotics can sustain the balance of intestinal bacteria and promote maturation of the gastrointestinal function, while reducing the incidence of feeding intolerance in premature neonates; thus, probiotics have been widely used in the treatment of gastrointestinal diseases in infants $(26,27)$. In the present study, the daily mean milk intake was significantly higher in the observation group $(16.57 \pm 2.58 \mathrm{ml})$ than in the control group $(13.26 \pm 1.87 \mathrm{ml} ; \mathrm{P}<0.001)$, which suggested that probiotics can facilitate the recovery of gastrointestinal function of term neonates with low Apgar scores. Probiotics treatment could reduce the stress response and accelerated the recovery of gastrointestinal function. Probiotics interact with other anaerobic bacteria to form a natural barrier, which can efficiently reduce or even block the contact of intestinal mucosa with pathogenic microorganisms (28). Additionally, probiotics can induce the immune response, enhance cellular immunity and mitigate stress responses $(29,30)$.

In summary, the administration of probiotics in combination with standard treatment could mitigate the stress response and decreased the intestinal permeability of term neonates with low Apgar scores to protect and facilitate gastrointestinal function recovery. Therefore, the results of the present study provided a theoretical basis for clinical treatment and contribute to the wide application of probiotics in clinical practice.

\section{Acknowledgements}

Not applicable.

\section{Funding}

No funding was received. 


\section{Availability of data and materials}

The datasets used and/or analyzed during the current study are available from the corresponding author on reasonable request.

\section{Authors' contributions}

JW conceived and designed the study and interpreted the results of the experiments. JZ and YH contributed to the design of the study and the interpretation of experimental results. JC performed experiments, analyzed data, prepared figures and drafted the manuscript. JW and YH approved final version of manuscript. YH edited and revised manuscript.

\section{Ethics approval and consent to participate}

This study was approved by the Ethics Committee of The Second Hospital of Lanzhou University, and the family of each neonate provided written informed consent.

\section{Patient consent for publication}

Not applicable.

\section{Competing interests}

The authors declare that they have no competing interests.

\section{References}

1. Koyama S, Kaga K, Sakata H, Iino Y and Kodera K: Pathological findings in the temporal bone of newborn infants with neonatal asphyxia. Acta Otolaryngol 125: 1028-1032, 2005.

2. Nisar M, Sabir H and Ahad Z: Etiological causes of respiratory distress syndrome in full term neonates presenting within 24 hours of life. Pakistan Journal of Medical and Health Sciences 11: 460-462, 2017.

3. Chen CC, Li LZ, Lu QS and Lang YL: Color Doppler ultrasound evaluation of asphyxial neonatal left ventricular function and its correlation with target organ damage. J Hainan Med Univ 23 147-150, 2017 (In Chinese).

4. Shankaran S, Laptook AR, Pappas A, McDonald SA, Das A, Tyson JE, Poindexter BB, Schibler K, Bell EF, Heyne RJ, et al: Effect of depth and duration of cooling on deaths in the NICU among neonates with hypoxic ischemic encephalopathy: A randomized clinical trial. JAMA 312: 2629-2639, 2014.

5. Seikku L, Gissler M, Andersson S, Rahkonen P, Stefanovic V, Tikkanen M, Paavonen J and Rahkonen L: Asphyxia, neurologic morbidity, and perinatal mortality in early-term and postterm birth. Pediatrics 137: e20153334, 2016.

6. Roro EM, Sisay MM and Sibley LM: Determinants of perinatal mortality among cohorts of pregnant women in three districts of north showa zone, oromia region, ethiopia: Community based nested case control study. BMC Public Health 18: 888, 2018.

7. Dalili H, Nili F, Sheikh M, Hardani AK, Shariat M and Nayeri F: Comparison of the four proposed apgar scoring systems in the assessment of birth asphyxia and adverse early neurologic outcomes. PLoS One 10: e0122116, 2015.

8. Cnattingius S, Norman M, Granath F, Petersson G, Stephansson O and Frisell T: Apgar score components at 5 minutes: Risks and prediction of neonatal mortality. Paediatric Perinat Epidemiol 31: 328-337, 2017.

9. Su Q, Zhang H, Zhang Y, Zhang H, Ding D, Zeng J, Zhu Z and Li H: Maternal stress in gestation: Birth outcomes and stress-related hormone response of the neonates. Pediatr Neonatol 56: 376-381, 2015.

10. Yao A, Jianling L, Xia L, Yao L, Wang Y and Yang H: The influences of DAO and SNGF in the treatment of hypothermia for neonates after birth asphyxia. Chin J Primary Med Pharm 23: 387-390, 2016.

11. Chalak LF: Inflammatory biomarkers of birth asphyxia. Clin Perinatol 43: 501-510, 2016
12. AlFaleh $\mathrm{K}$ and Anabrees $\mathrm{J}$ : Probiotics for prevention of necrotizing enterocolitis in preterm infants. Evid Based Child Health 9: 584-671, 2014.

13. Nuñez IN, Perdigón G and Galdeano CM: Chapter 6 - Immune System in Undernourished Host: Probiotics as Strategy to Improve Immunity. In: Nutrients in dairy and their implications on health and disease. Watson RR, Collier RJ and Preedy VR (eds). Elsevier, Amsterdam, pp77-86, 2018.

14. Persson M, Razaz N, Tedroff K, Joseph KS and Cnattingius S: Five and 10 minute apgar scores and risks of cerebral palsy and epilepsy: Population based cohort study in Sweden. BMJ 360: $\mathrm{k} 207,2018$.

15. Laptook AR, Shankaran S, Ambalavanan N, Carlo WA, McDonald SA, Higgins RD and Das A; Hypothermia Subcommittee of the NICHD Neonatal Research Network: Outcome of term infants using apgar scores at 10 minutes following hypoxic-ischemic encephalopathy. Pediatrics 124: 1619-1626, 2009.

16. Dupont C, Kalach N and Rousseau V: Gastrointestinal Problems of the Newborn. In: Textbook of Pediatric Gastroenterology, Hepatology and Nutrition. Guandalini S, Dhawan A and Branski D (eds). Springer, Basel, pp41-52, 2016.

17. Neu J: Preterm infant nutrition, gut bacteria, and necrotizing enterocolitis. Curr Opin Clin Nutr Metab Care 18: 285-288, 2015.

18. Halpern MD and Denning PW: The role of intestinal epithelial barrier function in the development of NEC. Tissue Barriers 3: e1000707, 2015.

19. Alvarez CS, Badia J, Bosch M, Giménez R and Baldomà L: Outer membrane vesicles and soluble factors released by probiotic escherichia coli nissle 1917 and commensal ECOR63 enhance barrier function by regulating expression of tight junction proteins in intestinal epithelial cells. Front Microbiol 7: 1981, 2016.

20. Kovacs K, Szakmar E, Meder U, Cseko A, Szabo AJ, Szabo M and Jermendy A: Serum cortisol levels in asphyxiated infants with hypotension. Early Hum Dev 120: 40-45, 2018.

21. Liu RJ, Ota KT, Dutheil S, Duman RS and Aghajanian GK: Ketamine strengthens CRF-activated amygdala inputs to basal dendrites in $\mathrm{mPFC}$ layer $\mathrm{V}$ pyramidal cells in the prelimbic but not infralimbic subregion, a key suppressor of stress responses. Neuropsychopharmacology 40: 2066-2075, 2015.

22. Shrivastava AK, Singh HV, Raizada A and Singh SK: C-reactive protein, inflammation and coronary heart disease. Egypt Heart J 67: 89-97, 2015

23. Ficek J, Wyskida K, Ficek R, Wajda J, Klein D, Witkowicz J, Rotkegel S, Spiechowicz-Zatoń U, Kocemba-Dyczek J, Ciepał J, et al: Relationship between plasma levels of zonulin, bacterial lipopolysaccharides, D-lactate and markers of inflammation in haemodialysis patients. Inter Urol Nephrol 49: 717-725, 2017.

24. Meng Y, Zhang Y, Liu M, Huang YK, Zhang J, Yao Q, Ling Zhao Y and Jing Xiong J: Evaluating intestinal permeability by measuring plasma endotoxin and diamine oxidase in children with acute lymphoblastic leukemia treated with high-dose methotrexate. Anticancer Agents Med Chem 16: 387-392, 2016.

25. Ochi F, Higaki T, Ohta M, Yamauchi T, Tezuka M, Chisaka T, Moritani T, Tauchi $\mathrm{H}$ and Ishii E: Procalcitonin as a marker of respiratory disorder in neonates. Pediatr Int 57: 263-268, 2015.

26. Alderliesten T, de Vries LS, Staats L, van Haastert IC, Weeke L, Benders MJ, Koopman-Esseboom C and Groenendaal F: MRI and spectroscopy in (near) term neonates with perinatal asphyxia and therapeutic hypothermia. Arch Dis Child Fetal Neonatal Ed 102: F147-F152, 2017

27. Amara AA and Shibl A: Role of probiotics in health improvement, infection control and disease treatment and management. Saudi Pharm J 23: 107-114, 2015.

28. Servin AL and Coconnier MH: Adhesion of probiotic strains to the intestinal mucosa and interaction with pathogens. Best Pract Res Clin Gastroenterol 17: 741-754, 2003.

29. Dolpady J, Sorini C, Di Pietro C, Cosorich I, Ferrarese R, Saita D, Clementi M, Canducci F and Falcone M: Oral probiotic VSL\#3 prevents autoimmune diabetes by modulating microbiota and promoting indoleamine 2,3-Dioxygenase-Enriched tolerogenic intestinal environment. J Diabetes Res 2016: 7569431, 2016.

30. Dawood MAO, Koshio S, Ishikawa M,El-Sabagh M, Esteban MA and Zaineldin AI: Probiotics as an environment-friendly approach to enhance red sea bream, pagrus major growth, immune response and oxidative status. Fish ShellfiSh Immunol 57: 170-178, 2016.

This work is licensed under a Creative Commons Attribution-NonCommercial-NoDerivatives 4.0 International (CC BY-NC-ND 4.0) License. 